\title{
The Hafnium-Platinum Phase Diagram
}

\author{
Judith K. Stalick and Richard M. Waterstrat
}

(Submitted August 30, 2013; in revised form September 26, 2013; published online October 29, 2013)

\begin{abstract}
Phase relationships were determined in the $\mathrm{Hf}-\mathrm{Pt}$ system at temperatures up to $1690{ }^{\circ} \mathrm{C}$ using both metallographic and neutron Rietveld refinement techniques. An unusual displacive transformation is observed below $200{ }^{\circ} \mathrm{C}$ in the rhombohedral compound $\mathrm{Hf}_{3} \mathrm{Pt}_{4}$, similar to that recently discovered in the compound $\mathrm{Zr}_{3} \mathrm{Pt}_{4}$. Crystallographic data are presented for the compounds $\mathrm{HfPt}_{4}, \mathrm{HfPt}_{3}, \mathrm{Hf}_{2} \mathrm{Pt}_{3}, \mathrm{Hf}_{3} \mathrm{Pt}_{4}, \mathrm{HfPt}$, and $\mathrm{Hf}_{2} \mathrm{Pt}$. A complete phase diagram is presented for the Hf-Pt binary system.
\end{abstract}

Keywords experimental crystal structure, experimental phase equilibria, intermetallic compound, phase diagram, phase transitions

\section{Introduction}

Among the binary compounds that are composed entirely of transition elements, we may select certain classes as being worthy of special attention. One such class would be those compounds which combine elements rich in $d$ electrons, such as $\mathrm{Ni}, \mathrm{Pd}$ and $\mathrm{Pt}$, with elements that are much more poorly supplied with them, such as $\mathrm{Ti}, \mathrm{Zr}$ and Hf. The cohesive energies in these compounds are exceptionally high ${ }^{[1]}$ and act to stabilize the equiatomic B2-type structures which are normally observed at high temperatures. However, at lower temperatures, the B2-type structures are often destabilized with respect to lower symmetry B2 derivative structures at temperatures ranging from $\approx 30{ }^{\circ} \mathrm{C}$ for $\mathrm{TiNi}$ to over $1600{ }^{\circ} \mathrm{C}$ for HfPt (see below). When temperatures are too low to permit transformations to proceed by nucleation and growth mechanisms, this class of compounds readily undergoes displacive transformation such as the one that occurs in the well-known TiNi compound.

Equiatomic compounds of the first long period elements $\mathrm{Ni}$ and $\mathrm{Ti}$ are of course noted for their shape memory effects and pseudoelasticity. Their successful commercial development in a variety of special applications has stimulated research on other compounds of this class. The compound $\mathrm{ZrPd}$ is the second long period analog of TiNi and is the basis of alloys having exceptional resistance to sliding wear. $^{[2]}$ The compound HfPt is the third long period analog

Judith K. Stalick, NIST Center for Neutron Research, National Institute of Standards and Technology, Gaithersburg, MD 20899, USA; Richard M. Waterstrat, Metallurgy Division, National Institute of Standards and Technology, Gaithersburg, MD 20899, USA. Contact e-mail: judith.stalick@nist.gov. of TiNi but its properties are not well known, due partly to the absence of a phase diagram for the Hf-Pt alloy system. The Hf-Pt system has become the last binary alloy system belonging to this class for which no phase diagram currently exists. It is the purpose of this study to provide one.

\section{Experimental Procedures}

All samples were prepared by arc-melting in a 50\% argon-helium atmosphere; melting losses were always less than $1 \%$. Energy-dispersive spectroscopy (EDS) was used to confirm that the sample compositions were in satisfactory agreement with the intended values. The starting materials were Pt sheet of $99.9 \%$ purity and iodide process (crystal bar) $\mathrm{Hf}$ containing $3 \mathrm{wt} . \% \mathrm{Zr}$ and less than $0.2 \%$ of other impurities. All samples were arc-melted four times and most were then arc-cast in a water-cooled copper mold to produce rods of $0.635 \mathrm{~cm}(1 / 4 \mathrm{in}$.) diameter and $5-7.5 \mathrm{~cm}$ in length. Samples were rapidly cooled by turning off the furnace power, and the cast rods generally cooled sufficiently to be handled with bare hands in about $15 \mathrm{~s}$ after casting. Compositional segregation in these rapidly cooled samples was apparently insignificant since the neutron diffraction patterns obtained at various high temperatures changed little during repeated scans lasting 2-6 h. No additional homogenization treatments were therefore undertaken.

Solidus temperatures were determined by visual observation of incipient melting on small $(\approx 1 \mathrm{~g})$ samples supported by high-purity alumina crucibles below $1600{ }^{\circ} \mathrm{C}$ or by thin $\mathrm{W}$ wire at higher temperatures. Solidus measurements were done in a high-vacuum furnace heated by Ta strips. Temperatures were placed on the international practical temperature scale (IPTS) by calibrating the hotzone current against secondary standards such as the observed melting points of high-purity $\mathrm{Ni}, \mathrm{Pt}$, and $\mathrm{Rh}$ wires.

$\mathrm{X}$-ray diffraction patterns were obtained at room temperature using $\mathrm{CuK}_{\alpha}$ radiation. Powder samples for these studies were prepared by grinding the alloys in a porcelain mortar and pestle. Internal strains were removed whenever necessary by annealing the powder in Ta foil containers suspended in the high-vacuum furnace.

Neutron diffraction data were collected using the BT-1 32-detector high-resolution powder diffractometer at the 
NIST Center for Neutron Research, over the range $3^{\circ} 2 \theta$ to $165^{\circ} 2 \theta$. Room-temperature patterns were obtained using a sample spinner to eliminate potential preferred orientation effects. High-temperature patterns were obtained in a highvacuum furnace with a $\mathrm{Nb}$ heating element at temperatures up to $1670{ }^{\circ} \mathrm{C}$ using a $\mathrm{Cu}(311)$ monochromator $(\lambda=1.5401(1) \AA$ to $1.5404(1) \AA)$ with a take-off angle of $90^{\circ}$ and $15^{\prime}$ or $60^{\prime}$ incident collimation. The samples were suspended in the furnace by thin W (3\% Re) wire. Repeated 2-h scans were obtained at each temperature until no further changes were observed prior to data collection. Roomtemperature data sets were also obtained using the $\mathrm{Ge}(733)$ monochromator $(\lambda=1.1968(1) \AA$ with a take-off angle of $120^{\circ}$ ) when more accurate structural information was desired, and using the $\mathrm{Ge}(311)$ monochromator $\left(\lambda=2.0785(1) \AA\right.$ with a take-off angle of $\left.75^{\circ}\right)$ when necessary to differentiate primitive from centered cubic structures. In addition, low-resolution data were obtained on some samples at temperatures up to $1690{ }^{\circ} \mathrm{C}$ using the Wombat high-intensity powder diffractometer at the Bragg Institute of the Australian Nuclear Science and Technology Organisation (ANSTO) in order to locate approximate temperatures for phase transitions.

The neutron diffraction data sets were corrected for absorption, and the phase compositions and crystallographic structural parameters were determined using the Rietveld technique as implemented in the GSAS suite of programs ${ }^{[3]}$ with EXPGUI interface. ${ }^{[4]}$ In most cases it was possible to quantify all phases present using multi-phase refinement of the crystal structures of the constituent phases.

\section{Results}

The alloy chemistry of hafnium has a well-known tendency to resemble that of zirconium, and our previous study of the Zr-Pt system ${ }^{[5]}$ was therefore a helpful guide in selecting sample compositions for the Hf-Pt system. We have designated each of our samples by its intended (nominal) atomic composition and we describe here their behavior on heating. The crystallographic results presented in the following sections are summarized in Table 1.

\section{1 $\mathrm{HfPt}_{4}$}

$\mathrm{HfPt}_{4}$ has been reported to be isostructural with $\mathrm{AuCu}_{3}$, with variable stoichiometry ranging from 15 at. $\% \mathrm{Hf}$ to 23 at.\% Hf. ${ }^{[6]}$ Neutron diffraction patterns [using the $\mathrm{Cu}(311)$ monochromator] obtained during slow heating of cast $\mathrm{HfPt}_{4}$ remained essentially unchanged between 200 and $840{ }^{\circ} \mathrm{C}$. Rietveld analysis of the data indicated that the arc-cast sample was composed of mass fractions of approximately $44 \% \mathrm{HfPt}_{4}\left(\mathrm{AuCu}_{3}\right.$-type), 34\% $\mathrm{HfPt}_{3}\left(\mathrm{TiNi}_{3}\right.$-type) and $22 \%$ face-centered cubic (Pt,Hf) solid solution with assumed composition $\mathrm{Pt}_{0.9} \mathrm{Hf}_{0.1}$. Above $\approx 840{ }^{\circ} \mathrm{C}$ the $\mathrm{HfPt}_{3}$ phase disappeared. The sample was heated to $1400{ }^{\circ} \mathrm{C}$, and data sets were obtained at intervals from $1400{ }^{\circ} \mathrm{C}$ down to $200{ }^{\circ} \mathrm{C}$ on cooling; the phase composition gradually changed from mass fractions of $\approx 94 \% \mathrm{HfPt}_{4}$ and $6 \%$
(Pt,Hf) at $1400{ }^{\circ} \mathrm{C}$ to $88 \% \mathrm{HfPt}_{4}$ and $12 \%$ (Pt,Hf) at $200{ }^{\circ} \mathrm{C}$. Rietveld refinement of the structures using subsequent room-temperature data indicated similar phase fractions, with $a=3.9796(2) \AA$ for $\mathrm{HfPt}_{4}$ and $a=3.9557$ (2) $\AA$ for the $(\mathrm{Pt}, \mathrm{Hf})$ solid solution, in good agreement with those previously reported of 3.981(5) $\AA$ for $\mathrm{HfPt}_{4}$ and $3.95 \mathrm{~A}$ (value read from graph) for the saturated $(\mathrm{Pt}, \mathrm{Hf})$ terminal solid solution. ${ }^{[6]}$

The diffracted peak intensities produced by the atomic ordering in the $\mathrm{AuCu}_{3}$-type structure (space group $P m \overline{3} m$ ) are very weak and, therefore, the observed patterns of $\mathrm{HfPt}_{4}$ closely resemble those of a disordered solid solution phase (space group $F m \overline{3} m$ ). We therefore collected data at room temperature using the $\mathrm{Ge}(311)$ monochromator, which has no second-order component in the incident neutron beam owing to the diamond structure of germanium, and in addition has a greater incident flux. The observed pattern clearly shows a weak (100) reflection resulting from the primitive $\mathrm{AuCu}_{3}$-type lattice.

Finally, room-temperature data were collected with the $\mathrm{Ge}(733)$ monochromator, since the shorter wavelength and higher take-off angle give greater accuracy for the determination of site occupancies as well as better discrimination of the two component phases. Rietveld refinement using this data yielded a phase composition (mass fractions) of $83 \%$ $\mathrm{HfPt}_{4}$ and $17 \%(\mathrm{Pt}, \mathrm{Hf})$ solid solution, with agreement factors $\chi^{2}=1.7$ and $R_{\mathrm{wp}}=0.076$. The agreement between calculated and observed intensities for the high-angle portion of this neutron diffraction pattern is presented in Fig. 1, clearly showing that two phases are present. For the $\mathrm{HfPt}_{4}$ phase, the refined occupancies give a composition of $\left(\mathrm{Hf}_{x} \mathrm{Pt}_{1-x}\right) \mathrm{Pt}_{3}$ with $x=0.82(7)$, corresponding to a stoichiometry of $\mathrm{HfPt}_{3.88}(20.5$ at.\% Hf). Whereas this stoichiometry is not statistically different from the "ideal" $\left(\mathrm{Hf}_{0.8} \mathrm{Pt}_{0.2}\right) \mathrm{Pt}_{3}$ [or $\mathrm{HfPt}_{4}$ ] composition, the presence of the $(\mathrm{Pt}, \mathrm{Hf})$ solid solution supports the conclusion that less $\mathrm{Pt}$ can be incorporated in the $\mathrm{AuCu}_{3}$-type structure at room temperature under equilibrium conditions than is implied by the formula $\mathrm{HfPt}_{4}$. Refinements of fractional occupancies indicate that the "extra" $\mathrm{Pt}$ is incorporated only on the $1 a$ crystallographic site $\left(\begin{array}{lll}0 & 0 & 0\end{array}\right)$ in the space group $P m \overline{3} m$ and that the $3 c$ site $\left(0 \frac{1}{2} \frac{1}{2}\right)$ is wholly occupied by Pt atoms, rather than having a random distribution of $\mathrm{Hf}$ and $\mathrm{Pt}$ atoms over the two sites. The diffraction peaks of the (Pt,Hf) solid solution are broader than the main phase peaks indicating a probable range of composition.

\section{2 $\mathrm{HfPt}_{3}$}

This sample was found to consist of $100 \%$ single phase $\mathrm{HfPt}_{3}$ (hexagonal $\mathrm{TiNi}_{3}$ type) in the as-cast condition, and it remained single phase when heated from room temperature to $900{ }^{\circ} \mathrm{C}$. Between 900 and $1200{ }^{\circ} \mathrm{C}$ a small amount $(<5 \%)$ of a second phase, identified as $\mathrm{Hf}_{2} \mathrm{Pt}_{3}$, appeared which was still developing at $1500{ }^{\circ} \mathrm{C}$ and then stabilized at $1540{ }^{\circ} \mathrm{C}$. In addition, a lesser amount of unidentified diffraction peaks were present, which could be due to the formation of a superstructure. Upon cooling to room temperature, the annealed sample consisted of only two phases: $97 \% \mathrm{HfPt}_{3}$ and $3 \% \mathrm{Hf}_{2} \mathrm{Pt}_{3}$ (isostructural with the 
Table 1 Crystallographic data for compounds in the Hf-Pt system

\begin{tabular}{|c|c|c|c|c|c|c|c|c|}
\hline Phase & Space group & Structure type & $a, \AA$ & $b, \AA$ & $c, \AA$ & $Z$ & $T,{ }^{\circ} \mathrm{C}$ & Comments \\
\hline \multirow[t]{4}{*}{$\mathrm{Pt}_{0.9} \mathrm{Hf}_{0.1}$} & $F m \overline{3} m$ & $\mathrm{Cu}$ & $3.9557(2)$ & & & 4 & 22 & Composition assumed; multi-phase sample \\
\hline & & & $3.9787(3)$ & & & & 600 & \\
\hline & & & $3.9938(3)$ & & & & 1000 & \\
\hline & & & $4.0161(3)$ & & & & 1400 & \\
\hline \multirow[t]{4}{*}{$\mathrm{HfPt}_{4}$} & $P m \overline{3} m$ & $\mathrm{AuCu}_{3}$ & $3.9796(2)$ & & & 1 & 22 & $\left(\mathrm{Hf}_{x} \mathrm{Pt}_{1-x}\right) \mathrm{Pt}_{3}, x=0.82(7)$ \\
\hline & & & $4.0015(2)$ & & & & 600 & \\
\hline & & & $4.0155(2)$ & & & & 1000 & \\
\hline & & & $4.0310(2)$ & & & & 1400 & \\
\hline \multirow[t]{4}{*}{$\mathrm{HfPt}_{3}$} & $\mathrm{P} 6_{3} / \mathrm{mmc}$ & $\mathrm{TiNi}_{3}$ & $5.6353(2)$ & & $9.216(1)$ & 4 & 22 & As-cast \\
\hline & & & $5.6348(2)$ & & $9.223(1)$ & & 22 & Annealed at $1500{ }^{\circ} \mathrm{C}$ for $6 \mathrm{~h}$ \\
\hline & & & $5.6761(2)$ & & $9.309(1)$ & & 900 & \\
\hline & & & $5.7037(2)$ & & $9.384(1)$ & & 1500 & \\
\hline \multirow[t]{3}{*}{$\mathrm{Hf}_{2} \mathrm{Pt}_{3}$} & $\mathrm{Cmcm}$ & $\mathrm{Ti}_{2} \mathrm{Pd}_{3}$ & 14.653(1) & $4.8741(3)$ & $4.8671(3)$ & 4 & 22 & From Ref ${ }^{[9]}$; stable to $1630 \pm 10^{\circ} \mathrm{C}$ \\
\hline & & & $14.883(1)$ & $4.9132(5)$ & $4.9101(5)$ & & 1200 & \\
\hline & & & $14.957(1)$ & $4.9217(7)$ & $4.9190(7)$ & & 1500 & \\
\hline $\mathrm{Hf}_{3} \mathrm{Pt}_{4}$ & unknown & & & & & & 22 & Low-temperature form; exists below $140^{\circ} \mathrm{C}$ \\
\hline \multirow{3}{*}{$\mathrm{Hf}_{3} \mathrm{Pt}_{4}$} & $R \overline{3}$ & $\mathrm{Pu}_{3} \mathrm{Pd}_{4}$ & $12.455(1)$ & & $5.5410(4)$ & 6 & 200 & Forms at $\approx 140$ to $170{ }^{\circ} \mathrm{C}$ on heating \\
\hline & & & $12.520(1)$ & & $5.5805(4)$ & & 900 & \\
\hline & & & $12.591(1)$ & & $5.6231(5)$ & & 1500 & \\
\hline \multirow[t]{4}{*}{$\mathrm{HfPt}$} & $\mathrm{Cmcm}$ & $\mathrm{CrB}$ & $3.3524(2)$ & $10.255(1)$ & $4.2870(2)$ & 4 & 22 & Low-temperature form \\
\hline & & & $3.3892(2)$ & $10.296(1)$ & $4.2891(3)$ & & 1000 & \\
\hline & & & $3.4092(3)$ & $10.317(1)$ & $4.3519(4)$ & & 1500 & \\
\hline & & & $3.4150(3)$ & $10.327(2)$ & $4.3590(5)$ & & 1655 & Some B2-type phase present \\
\hline $\mathrm{HfPt}$ & $P m \overline{3} m$ & $\mathrm{~B} 2$ & $3.3623(2)$ & & & 1 & 1669 & Forms above $1660 \pm 10^{\circ} \mathrm{C}$ \\
\hline \multirow[t]{3}{*}{$\mathrm{Hf}_{2} \mathrm{Pt}$} & $F d \overline{3} m$ & $\mathrm{Ti}_{2} \mathrm{Ni}$ & $12.467(2)$ & & & 32 & 22 & Alloy comp. $\mathrm{Hf}_{95} \mathrm{Pt}_{5} ;$ multiphase sample \\
\hline & & & $12.557(2)$ & & & & 1000 & Alloy comp. $\mathrm{Hf}_{85} \mathrm{Pt}_{15}$; multiphase sample \\
\hline & & & $12.593(2)$ & & & & 1320 & Alloy comp. $\mathrm{Hf}_{85} \mathrm{Pt}_{15}$; multiphase sample \\
\hline \multirow[t]{5}{*}{$\alpha-\mathrm{Hf}$} & $\mathrm{P} 6_{3} / \mathrm{mmc}$ & $\mathrm{Mg}$ & $3.1796(3)$ & & $5.0696(4)$ & 2 & 22 & Alloy composition $\mathrm{Hf}_{95} \mathrm{Pt}_{5}$ \\
\hline & & & $3.218(1)$ & & $5.114(1)$ & & 1000 & \\
\hline & & & $3.221(1)$ & & $5.130(1)$ & & 1300 & No $\beta$-Hf phase present \\
\hline & & & $3.222(1)$ & & $5.142(1)$ & & 1400 & $\approx 63 \% \alpha$-Hf and $37 \% \beta$-Hf \\
\hline & & & $3.227(1)$ & & $5.146(2)$ & & 1458 & $\approx 45 \% \alpha$-Hf and $55 \% \beta$-Hf \\
\hline \multirow[t]{2}{*}{$\beta$-Hf } & $\operatorname{Im} \overline{3} m$ & $\mathrm{~W}$ & $3.557(1)$ & & & 2 & 1400 & $\approx 63 \% \alpha-\mathrm{Hf}$ and $37 \% \beta$-Hf \\
\hline & & & $3.564(1)$ & & & & 1458 & $\approx 45 \% \alpha$-Hf and $55 \% \beta$-Hf \\
\hline
\end{tabular}

Standard uncertainties are given in parentheses. Where data have been determined over a broad temperature range, only values at selected temperatures are given

low-temperature form of $\mathrm{Ti}_{2} \mathrm{Ni}_{3}$; see "Hf2Pt3" section below). The hexagonal a lattice parameter of the $\mathrm{HfPt}_{3}$ phase was essentially the same in the as-cast and annealed samples, with $a=5.6353(2)$ and 5.6348(2) A, respectively; however, the $c$ lattice parameter changed significantly on annealing, with $c=9.216(1) \AA$ as-cast and 9.223(1) $\AA$ after annealing. By comparison, Dwight and Beck $^{[7]}$ report values of $a=5.636$ and $c=9.208 \AA$ for a sample annealed at $900{ }^{\circ} \mathrm{C}$ for 5 days; the small variation in the $c$ lattice parameter might possibly indicate a slightly different sample composition.

Metallographic and x-ray diffraction studies on samples rapidly cooled from 1700 and $1800{ }^{\circ} \mathrm{C}$ indicated that the $\mathrm{HfPt}_{3}$ structure is probably stable over a composition range of several percent at high temperature. This composition range narrows at lower temperatures, however.

\section{3 $\mathrm{Hf}_{2} \mathrm{Pt}_{3}$}

Raman and Schubert ${ }^{[8]}$ reported finding a phase described as $\mathrm{Hf}_{2} \mathrm{Pt}_{3}$ having a tetragonal $\mathrm{MoSi}_{2}$-type structure with $a=3.43$ and $c=8.73 \AA$. However, the diffraction pattern of this phase only resembles that of a $\mathrm{MoSi}_{2}$-type structure at relatively low scattering angles; several additional reflections are apparent above $60^{\circ} 2 \theta(\lambda=1.5401 \AA)$. Using neutron and electron diffraction techniques, we have recently reported ${ }^{[9]}$ that this compound actually possesses a $\mathrm{Ti}_{2} \mathrm{Pd}_{3}$ type structure, ${ }^{[10]}$ space group $\mathrm{Cmcm}$, and is isostructural with the low-temperature form of $\mathrm{Ti}_{2} \mathrm{Ni}_{3} \cdot{ }^{[11]}$ Reexamination of the high-temperature neutron diffraction data indicates that this phase is stable up to $\approx 1630{ }^{\circ} \mathrm{C}$ (rather than the $1659{ }^{\circ} \mathrm{C}$ previously reported), where it decomposes in a peritectoid reaction to form $\mathrm{Hf}_{3} \mathrm{Pt}_{4}$ and $\mathrm{HfPt}_{3}$. 


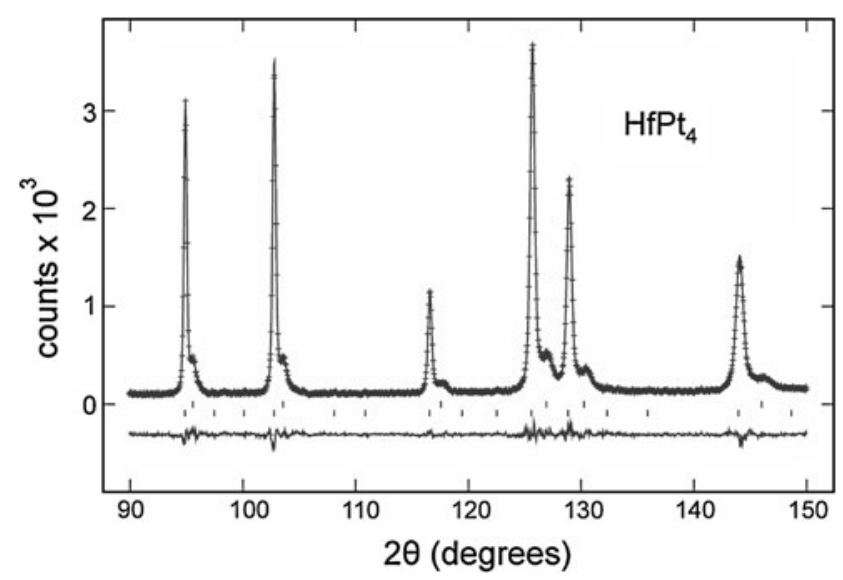

Fig. 1 Observed (+), calculated (solid line) and difference patterns for the high-angle portion for the neutron Rietveld refinement of $\mathrm{HfPt}_{4}$ [data using the $\mathrm{Ge}(733)$ monochromator, $\lambda=1.1968(1) \AA]$. Lower hash marks indicate the calculated positions for the $\mathrm{HfPt}_{4}$ reflections $\left(\mathrm{AuCu}_{3}\right.$ type, with composition $\left.\left(\mathrm{Hf}_{0.82} \mathrm{Pt}_{0.18}\right) \mathrm{Pt}_{3}\right)$, and the upper hash marks indicate the Cu-type $\mathrm{Pt}_{0.9} \mathrm{Hf}_{0.1}$ solid solution with reflections shifted to slightly higher scattering angles

\section{4 $\mathrm{Hf}_{3} \mathrm{Pt}_{4}$}

This compound, which has not previously been recognized to exist as a definite compound in the Hf-Pt system, exhibits a complex diffraction pattern at room temperature. However, slightly above room temperature there is a phase transformation to a rhombohedral $\mathrm{Pu}_{3} \mathrm{Pd}_{4}$-type structure. This structure type was first determined in $1973 .{ }^{[12]}$ Since then, more than three dozen intermetallic compounds have been reported to possess this structure type. We have previously reported that one of these compounds, $\mathrm{Zr}_{3} \mathrm{Pt}_{4}$, undergoes a low-temperature phase transformation from a complex room-temperature form to the $\mathrm{Pu}_{3} \mathrm{Pd}_{4}$ structure type on heating between 90 and $120{ }^{\circ} \mathrm{C} .{ }^{[5]}$ We have found that $\mathrm{Hf}_{3} \mathrm{Pt}_{4}$ belongs to this same class of compounds, with a phase transition temperature between 140 and $170{ }^{\circ} \mathrm{C}$. Whereas the structure of the room temperature forms of these materials has not been definitively determined, we were able to fit the low-angle portions of the neutron diffraction patterns of both $\mathrm{Hf}_{3} \mathrm{Pt}_{4}$ and $\mathrm{Zr}_{3} \mathrm{Pt}_{4}$ using Rietveld refinement with an approximate model that is a triclinic distortion of the rhombohedral lattice. Thus, the two materials are isostructural at both room temperature and at $200{ }^{\circ} \mathrm{C}$. Thermal expansion vs. temperature measurements on $\mathrm{Zr}_{3} \mathrm{Pt}_{4}$ have shown that the transformation is reversible and exhibits a hysteresis effect. ${ }^{[5]}$ We observed similar behavior in our neutron diffraction studies on both $\mathrm{Zr}_{3} \mathrm{Pt}_{4}$ and $\mathrm{Hf}_{3} \mathrm{Pt}_{4}$; the samples were homogenized by annealing at high temperature before conducting the lower temperature studies, and the reversible nature of the structural transformations was confirmed for both materials. Figure 2 presents the results of the neutron refinements for $\mathrm{Hf}_{3} \mathrm{Pt}_{4}$ both at room temperature and at $200{ }^{\circ} \mathrm{C}$. The refinement at $200{ }^{\circ} \mathrm{C}$ clearly shows the presence of some impurity peaks, most likely from the composition $\mathrm{Hf}_{45} \mathrm{Pt}_{55}$ which does not transform under these conditions (see below). [We have also discovered a similar transition in the compound $\mathrm{Zr}_{3} \mathrm{Rh}_{4},{ }^{[13]}$ with a transition temperature between 70 and $170{ }^{\circ} \mathrm{C}$. Although this material has been reported to be rhombohedral at room temperature, with an incommensurate structure based on the $\mathrm{Pu}_{3} \mathrm{Pd}_{4}$ structure type, ${ }^{[14]}$ it is possible that heating from the electron beam used for the study was sufficient to transform the sample].

The rhombohedral $\mathrm{Pu}_{3} \mathrm{Pd}_{4}$ structure type for $\mathrm{Hf}_{3} \mathrm{Pt}_{4}$ was found to exist at least up to $1690{ }^{\circ} \mathrm{C}$. Figure 3a shows a photomicrograph of an as-cast alloy of composition $\mathrm{Hf}_{41} \mathrm{Pt}_{59}$ exhibiting a finely-twinned structure characteristic of the displacive transformation of the rhombohedral phase below $200{ }^{\circ} \mathrm{C}$. Additionally, there is some photomicrographic evidence that $\mathrm{Hf}_{3} \mathrm{Pt}_{4}$ may undergo a further phase transformation above $1690^{\circ} \mathrm{C}$ but below $1800^{\circ} \mathrm{C}$. Figure $3 \mathrm{~b}$ shows a small region of a sample of composition $\mathrm{Hf}_{3} \mathrm{Pt}_{4}$, annealed at $1800^{\circ} \mathrm{C}$ for $1 \mathrm{~h}$ and rapidly cooled. Large decomposed grains are seen accompanied by diffusion, unlike the low-temperature transformation which is diffusionless. This high-temperature phase may be a B2type derivative, similar to that reported by Jorda et al. ${ }^{[15]}$ for $\mathrm{Zr}_{3} \mathrm{Rh}_{4}$ which is reported to be an equilibrium compound that forms on cooling by a solid state reaction from a B2 phase at $1660 \pm 20^{\circ} \mathrm{C}$. It is thus possible that there exists a continuous solid solution of the $\mathrm{HfPt}$ and $\mathrm{Hf}_{3} \mathrm{Pt}_{4}$ compounds at high temperature. However, we were unable to confirm this since our present apparatus does not permit operation in this temperature range.

\section{$3.5 \mathrm{Hf}_{45} \mathrm{Pt}_{55}$}

The neutron diffraction pattern of this alloy is not the same as that of the low-temperature form of $\mathrm{Hf}_{3} \mathrm{Pt}_{4}$ nor of the tetragonal $\mathrm{Zr}_{9} \mathrm{Pt}_{11}$ structure type, although it bears a strong resemblance to that of $\mathrm{Hf}_{3} \mathrm{Pt}_{4}$. We have been unable to determine its structure and, until further information becomes available, we have chosen not to depict it as a separate phase but as an extension of the $\mathrm{Hf}_{3} \mathrm{Pt}_{4}$ phase region brought about by a displacive transformation of some sort. The observed pattern, shown in Fig. 4, has much sharper neutron diffraction peaks than does $\mathrm{Hf}_{3} \mathrm{Pt}_{4}$. Attempts at structure refinement showed that both the HfPt and rhombohedral $\mathrm{Hf}_{3} \mathrm{Pt}_{4}$ phases were not present, and thus the pattern cannot be accounted for by a mixture of known phases.

This structure is surprisingly stable, having been observed at temperatures as high as $1610{ }^{\circ} \mathrm{C}$ without transformation to the rhombohedral $\mathrm{Pu}_{3} \mathrm{Pd}_{4}$ structure type. We note that the compound $\mathrm{Zr}_{9} \mathrm{Pt}_{11}$ has been shown to be metastable and forms as an extension of the $\mathrm{Zr}_{3} \mathrm{Pt}_{4}$ phase when atom vacancies are created at certain Pt atom sites. ${ }^{[16]}$ Unusual behavior of this sort may perhaps be necessary in order to form a $\mathrm{Hf}_{9} \mathrm{Pt}_{11}$ structure.

\subsection{HfPt}

HfPt has been reported to exist as the $\mathrm{CrB}$ structure type with $a=3.345(1), b=10.269(1)$ and $c=4.288(1) \AA^{[17]}$ An as-cast sample of HfPt was examined by neutron diffraction at room temperature and at temperatures up to $1670{ }^{\circ} \mathrm{C}$. A transformation from the room-temperature 


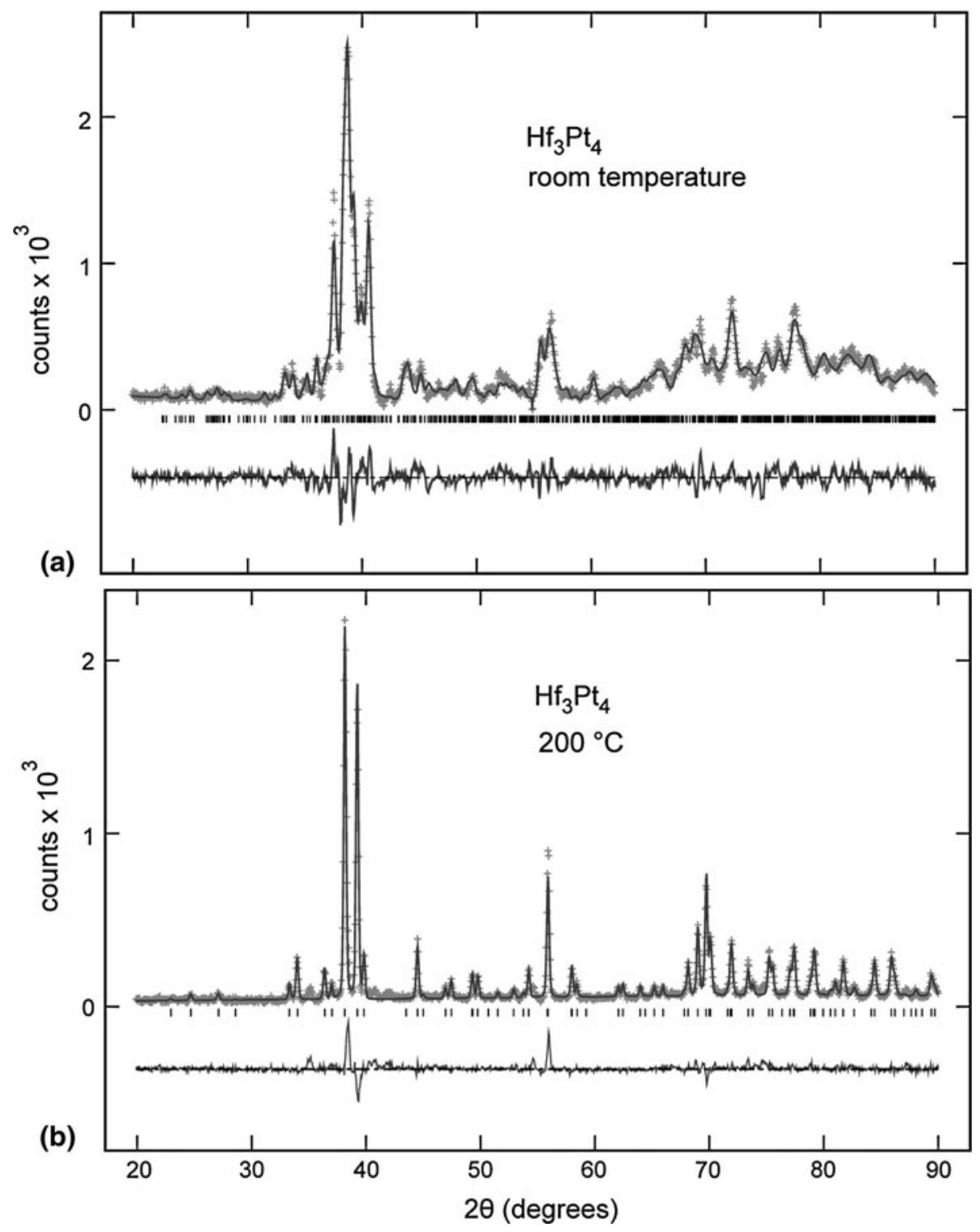

Fig. 2 Observed (+), calculated (solid line) and difference patterns for a portion of the neutron Rietveld refinements of $\mathrm{Hf}_{3} \mathrm{Pt}_{4}(\mathrm{a})$ at room temperature and (b) at $200{ }^{\circ} \mathrm{C}$ using the $\mathrm{Cu}(311)$ monochromator, $\lambda=1.5403(1) \AA$ [at $200{ }^{\circ} \mathrm{C}: \chi^{2}=2.00, R_{\mathrm{wp}}=0.13$, space group $R \overline{3}, Z=6, a=12.455(1) \AA, c=5.5410(4) \AA$; Hf in $18 f$ with $x=0.5518(3), y=0.8400(4), z=0.4447(7)$; $\operatorname{Pt}(1)$ in $1 a(000)$; Pt(2) in $1 b\left(\begin{array}{lll}0 & 0 & 1 / 2\end{array}\right) ; \operatorname{Pt}(3)$ in $18 f$ with $\left.x=0.2655(3), y=0.2140(3) z=0.2892(6)\right]$. Hash marks indicate calculated positions for the reflections. Standard uncertainties are given in parentheses

CrB-type structure $(a=3.3524(2), \quad b=10.255(1), \quad c=$ $4.2870(2) \AA)$ to a B2-type structure was observed at $1660 \pm 10^{\circ} \mathrm{C}$, with $a=3.3623(2) \AA$ at $1669^{\circ} \mathrm{C}$. This transition was also indicated by optical microscopy studies on a sample annealed at $1800{ }^{\circ} \mathrm{C}$ for $1 \mathrm{~h}$ in vacuum and rapidly cooled. Photomicrographs of the quenched sample show non-transformed areas indicating the existence of regions of the high-temperature B2-type phase (Fig. 5).

\section{7 $\mathrm{Hf}_{2} \mathrm{Pt}, \mathrm{Hf}_{85} \mathrm{Pt}_{15}$ and $\mathrm{Hf}_{95} \mathrm{Pt}_{5}$}

A small arc-cast sample of $\mathrm{Hf}_{2} \mathrm{Pt}$ was examined using $\mathrm{X}$-ray diffraction at room temperature. The cubic $\mathrm{Ti}_{2} \mathrm{Ni}$-type structure reported by Nevitt and Schwartz ${ }^{[18]}$ was confirmed.

An arc-cast rod of composition $\mathrm{Hf}_{85} \mathrm{Pt}_{15}$ was examined by neutron diffraction at temperatures up to $1360{ }^{\circ} \mathrm{C}$ where a reaction with the supporting $\mathrm{W}(3 \% \mathrm{Re})$ wire terminated the experiment. $\mathrm{Hf}_{2} \mathrm{Pt}$ and the hexagonal $\alpha$-Hf phases were observed starting at $1000{ }^{\circ} \mathrm{C}$, along with minor amounts of unidentified impurity phases; at $\approx 1240{ }^{\circ} \mathrm{C}$ the unidentified phases disappeared and the sample consisted of mass fractions of approximately $50 \% \mathrm{Hf}_{2} \mathrm{Pt}$ and $50 \% \alpha$ - $\mathrm{Hf}$.

A sample of composition $\mathrm{Hf}_{95} \mathrm{Pt}_{5}$ was also prepared; no room-temperature data were collected prior to heating. As the sample was rapidly heated from 35 to $1040{ }^{\circ} \mathrm{C}$ while 


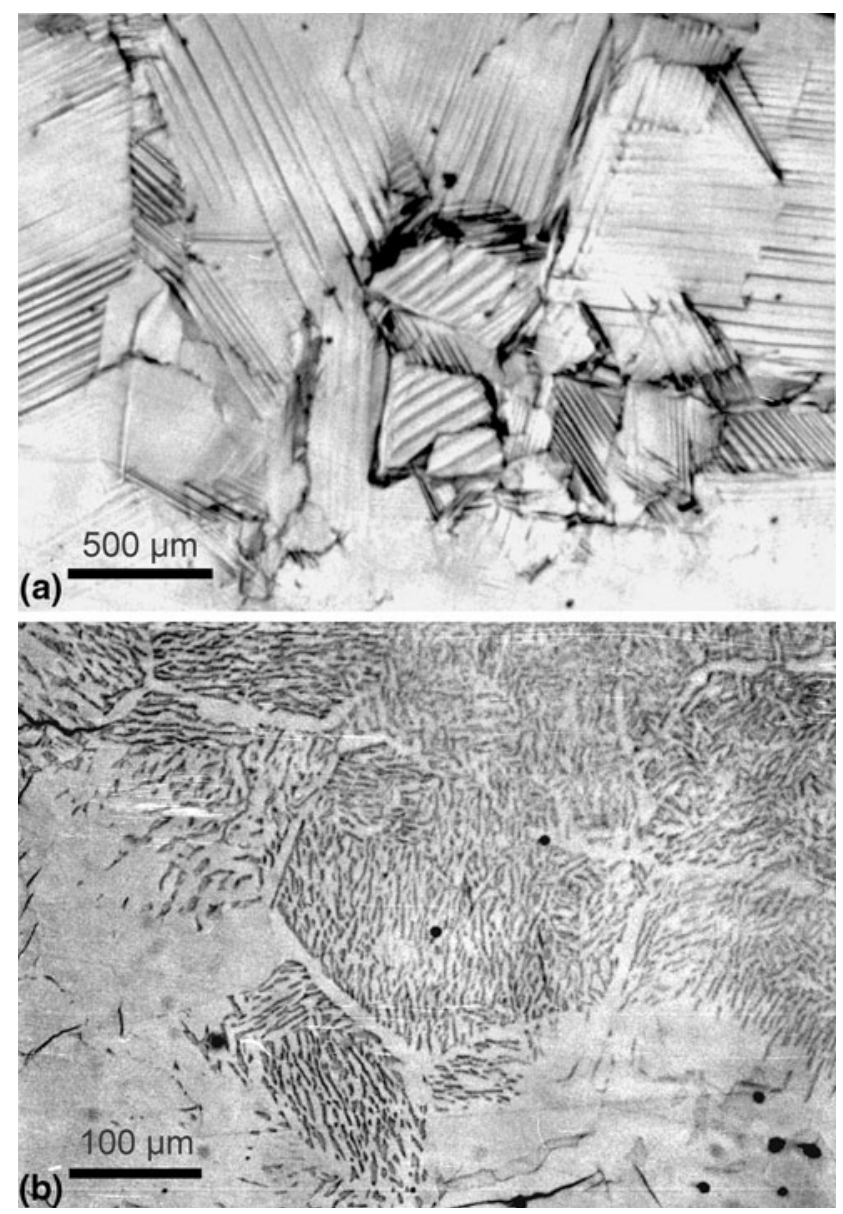

Fig. 3 Photomicrographs indicating phase transformations in $\mathrm{Hf}_{3} \mathrm{Pt}_{4}$. (a) Microstructure of the as-cast alloy of composition $\mathrm{Hf}_{41} \mathrm{Pt}_{59}$, exhibiting a finely-twinned structure produced by the displacive transformation characteristic of the rhombohedral $\mathrm{Hf}_{3} \mathrm{Pt}_{4}$ phase transition below $200{ }^{\circ} \mathrm{C}$. (b) Sample composition $\mathrm{Hf}_{3} \mathrm{Pt}_{4}$, annealed at $1800{ }^{\circ} \mathrm{C}$ for $1 \mathrm{~h}$ and rapidly cooled. The microstructure of this small region of the sample suggests a diffusion-controlled decomposition of large prior grains of a hightemperature phase. Photomicrographs of other areas of the sample, however, resemble that shown in Fig. 3a

simultaneously collecting neutron diffraction data, we observed primarily the $\alpha$-Hf phase. Data collected at $1300{ }^{\circ} \mathrm{C}$ revealed the coexistence of $85 \% \alpha$-Hf and $15 \%$ $\mathrm{Hf}_{2} \mathrm{Pt}$. At $1400{ }^{\circ} \mathrm{C}$ the amount of $\alpha$-Hf had decreased to a mass fraction of $65 \%$, the $\mathrm{Hf}_{2} \mathrm{Pt}$ phase was no longer present, and the cubic $\beta$-Hf phase had formed (35\%); this $\alpha \rightarrow \beta$ transformation temperature is in the same general range as that for pure $\alpha$-Hf $\rightarrow \beta$-Hf of $1310 \pm 10{ }^{\circ} \mathrm{C}$ reported by Duwez ${ }^{[19]}$. The amount of $\beta$-Hf increased to a mass fraction of $\approx 55 \%$ at $1458{ }^{\circ} \mathrm{C}$, with $a=3.564(1) \AA$ at this temperature. Upon cooling to room temperature, the sample composition was once again $85 \% \alpha$ - $\mathrm{Hf}$ and $15 \%$ $\mathrm{Hf}_{2} \mathrm{Pt}$. The lattice parameter obtained for $\mathrm{Hf}_{2} \mathrm{Pt}$ at room temperature was $a=12.467(2) \AA$, in good agreement with that of $12.461 \AA$ reported by Nevitt and Schwartz ${ }^{[18]}$ for a sample of composition $\mathrm{Hf}_{70} \mathrm{Pt}_{30}$. The lattice parameters

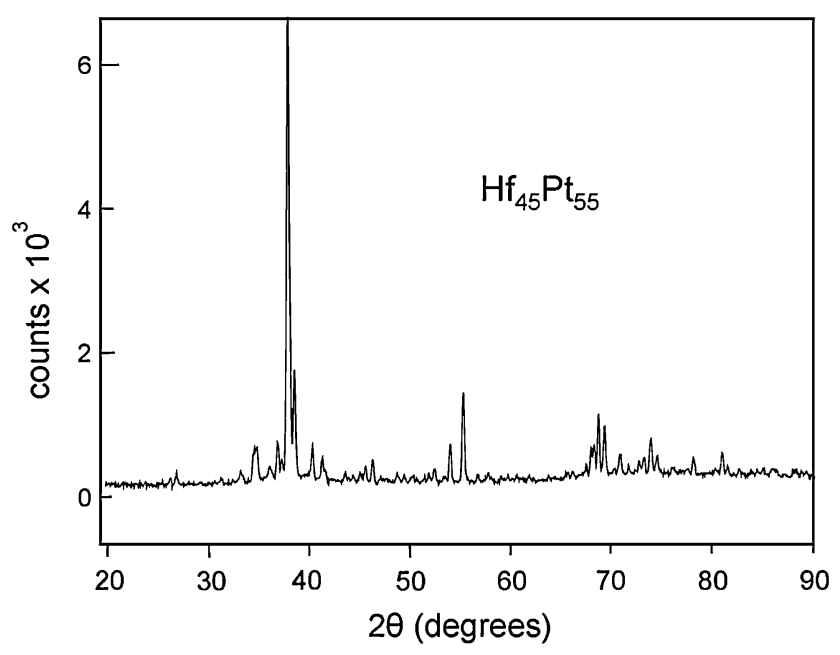

Fig. 4 Observed neutron diffraction pattern for $\mathrm{Hf}_{45} \mathrm{Pt}_{55}$, $\lambda=1.5403(1) \AA$. It is possible that this composition is actually a compound $\left(\mathrm{Hf}_{9} \mathrm{Pt}_{11}\right)$, but since the structure has not yet been determined we have chosen to describe this as an extension of the $\mathrm{Hf}_{3} \mathrm{Pt}_{4}$ phase

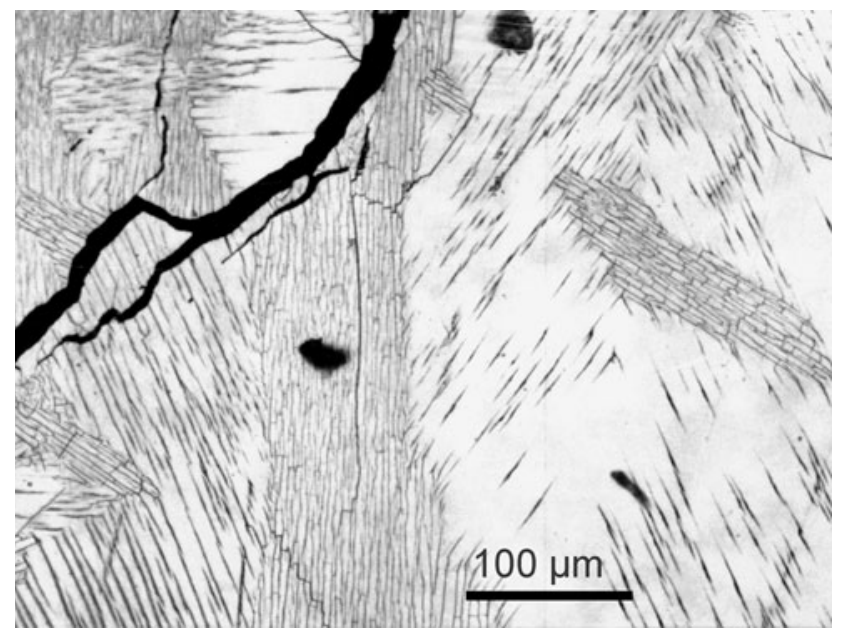

Fig. 5 Photomicrograph of $\mathrm{HfPt}$ annealed at $1800{ }^{\circ} \mathrm{C}$ for $1 \mathrm{~h}$ and then rapidly cooled. Striated regions of the low-temperature CrB-type phase are seen to be present in a matrix of retained high-temperature B2-type phase (light areas)

obtained for $\alpha$-Hf of $a=3.1796(3)$ and $c=5.0696(4)$ A agree reasonably well with those reported by Russell ${ }^{[20]}$ of $a=3.1964$ and $c=5.0511 \AA$ for $\alpha-\mathrm{Hf}$ with $3 \% \mathrm{Zr}$, indicating that little if any Pt is incorporated in the $\alpha-\mathrm{Hf}$ phase at room temperature.

\subsection{Hf-Pt Phase Diagram}

The Hf-Pt phase diagram that emerges from this study is shown in Fig. 6. We estimate that its accuracy in atomic composition is $\pm 0.5 \%$ and its accuracy in temperature is $\pm 10^{\circ} \mathrm{C}$ up to 1700 and $\pm 15{ }^{\circ} \mathrm{C}$ above $1700^{\circ} \mathrm{C}$. The invariant transformations in the Hf-Pt system are summarized in Table 2. 


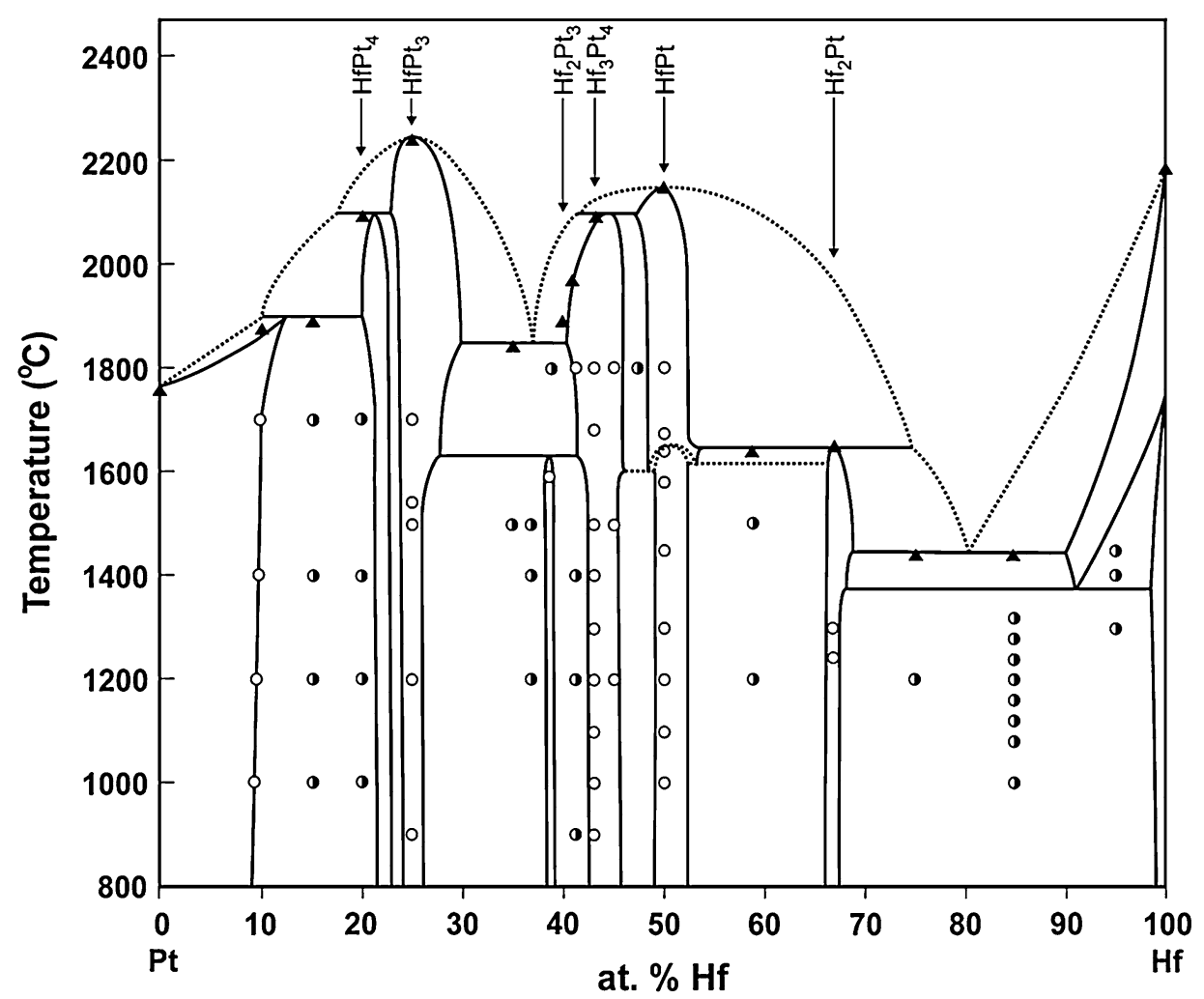

Fig. 6 The Hf-Pt phase diagram. The triangles indicate the onset of melting on heating; half-filled circles indicate a two-phase alloy; open circles indicate a single-phase alloy. All regions have had the chemical composition and crystal structures of each phase determined by neutron Rietveld refinement, as well as the relative amount of each phase present in two-phase regions, with the exception that points at 1700 and $1800{ }^{\circ} \mathrm{C}$ were obtained by optical microscopy

Table 2 Invariant transformations in Hf-Pt alloys

\begin{tabular}{llc}
\hline Type & \multicolumn{1}{c}{ Phases } & \multicolumn{1}{c}{$\boldsymbol{T}{ }^{\circ} \mathbf{C}$} \\
\hline Peritectic & $\left(\mathrm{Pt}_{0.9} \mathrm{Hf}_{0.1}\right) \rightleftarrows \mathrm{L}+\mathrm{HfPt}_{4}$ & $1910 \pm 15$ \\
Peritectic & $\mathrm{Hft}_{4} \rightleftarrows \mathrm{L}+\mathrm{HfPt}_{3}$ & $2100 \pm 15$ \\
Congruent & $\mathrm{Hft}_{3} \rightleftarrows \mathrm{L}$ & $2250 \pm 15$ \\
Eutectic & $\mathrm{Hft}_{3}+\mathrm{Hf}_{3} \mathrm{Pt}_{4} \rightleftarrows \mathrm{L}$ & $1850 \pm 15$ \\
Peritectoid & $\mathrm{Hf}_{2} \mathrm{Pt}_{3} \rightleftarrows \mathrm{HfPt}_{3}+\mathrm{Hf}_{3} \mathrm{Pt}_{4}$ & $1630 \pm 10$ \\
Peritectic & $\mathrm{Hf}_{3} \mathrm{Pt}_{4} \rightleftarrows \mathrm{L}+\mathrm{HfPt}$ & $2100 \pm 15$ \\
Congruent & $\mathrm{Hft}_{2} \rightleftarrows \mathrm{L}$ & $2160 \pm 15$ \\
Undetermined & $\mathrm{HfPt} \mathrm{CrB}$-type $) \rightleftarrows \mathrm{HfPt}(\mathrm{B} 2$-type $)$ & $1660 \pm 10$ \\
Peritectic & $\mathrm{Hf}_{2} \mathrm{Pt} \rightleftarrows \mathrm{L}+\mathrm{HfPt}$ & $1660 \pm 10$ \\
Eutectic & $\mathrm{Hf}_{2} \mathrm{Pt}+\beta$ - $\mathrm{Hf} \rightleftarrows \mathrm{L}$ & $1450 \pm 10$ \\
Eutectoid & $\mathrm{Hf}_{2} \mathrm{Pt}+\alpha$ - $\mathrm{Hf} \rightleftarrows \beta$-Hf & $1380 \pm 15$ \\
\hline
\end{tabular}

\section{Discussion}

The conventional practice of studying samples quenched from various temperatures was largely abandoned here in favor of using in situ high-temperature neutron diffraction methods. Gharghouri ${ }^{[21]}$ has pointed out some of the many advantages of using this technique to study alloy systems. The much larger neutron diffraction samples permit accurate, three-dimensional analysis of the phase fractions which is less influenced by preferred orientation effects and less subject to contamination than the fine powders used for $\mathrm{x}$-ray diffraction, particularly when samples are examined at high temperatures.

Neutron Rietveld analysis provides information about all phases that are present at each temperature, including the chemical composition and the crystal structure of each phase, as well as the component phase fractions of multiphase samples. With the simultaneous neutron data collection and annealing of the cast samples, one can follow the phase changes upon heating as well as determine the temperature at which the sample becomes homogeneous and the equilibrium structure is formed. This technique provides much more information than can be obtained with conventional EDX methods. Data obtained upon cooling shows that the equilibrium phases are retained, even when there is a reversible structural transformation that is observed above room temperature. Furthermore, the absorption problems associated with heavy elements such as $\mathrm{Hf}$ and $\mathrm{Pt}$ are far less serious for neutrons than for $\mathrm{x}$-rays. Thus, diffraction peak positions and intensities can be measured with greater accuracy; in addition, the larger range of scattering data available owing to the constancy of the neutron scattering form factor with $Q=4 \pi \sin \theta / \lambda$ allows for more accurate phase fraction and site occupancy determination. 
The significance of these results can be realized to some extent by comparing them with those of the $\mathrm{Zr}$-Pt system. ${ }^{[5]}$ One notes that $\mathrm{Zr}_{7} \mathrm{Pt}_{10}$ is apparently replaced by $\mathrm{Hf}_{2} \mathrm{Pt}_{3}$, and $\mathrm{Zr}_{5} \mathrm{Pt}_{3}$ is replaced by $\mathrm{Hf}_{2} \mathrm{Pt}$. The exceptional stability of the CrB-type compounds $\mathrm{ZrPt}$ and HfPt is also noteworthy. Both of these compounds have large negative heats of formation: $\mathrm{HfPt}$ has a measured value of $-227.3 \mathrm{~kJ} / \mathrm{mol}$ and $\mathrm{ZrPt}$ follows closely with $-191.9 \mathrm{~kJ} / \mathrm{mol}$ according to Topor and Kleppa ${ }^{[1]}$.

From recent ab-initio calculations based on density functional theory, Levy et al. ${ }^{[22]}$ were led to conclude that the B2-type structure is probably not stable at the equiatomic composition in HfPt. There is some experimental evidence, however, supporting the existence of a B2-type structure in a non-stoichiometric alloy described as "HfPt ${ }_{1+}$ " (i.e. Pt-rich HfPt). ${ }^{[8]}$ Whereas we found no B2type compounds to exist at room temperature, our sample of $\mathrm{HfPt}$, prepared at the equiatomic composition, clearly transforms to a cubic structure above $1660{ }^{\circ} \mathrm{C}$.

Large negative heats of formation have also been reported for the compounds $\mathrm{HfPt}_{3}$ and $\mathrm{ZrPt}_{3}$ with values of -118.7 and $-112.9 \mathrm{~kJ} / \mathrm{mol}$, respectively. ${ }^{[6]}$ Here, Levy et al. suggest that the "ideal" stoichiometric $\mathrm{HfPt}_{3}$ would have a $\mathrm{TiNi}_{3}$-type structure but, in alloys slightly more rich in $\mathrm{Pt}$, the $\mathrm{AuCu}_{3}$-type structure will be slightly more stable. Our experimental results support this conclusion, with the confirmation of the $\mathrm{AuCu}_{3}$-type structure for the composition $\mathrm{HfPt}_{4}$.

Lastly, alloys with the $\mathrm{Pu}_{3} \mathrm{Pd}_{4}$ structure type appear to possess unusual properties. A significant result of this investigation is the discovery of a low-temperature displacive transformation in the compound $\mathrm{Hf}_{3} \mathrm{Pt}_{4}$, as well as in $\mathrm{Zr}_{3} \mathrm{Rh}_{4}$ and the previously reported $\mathrm{Zr}_{3} \mathrm{Pt}_{4}{ }^{[5]}$ It may be noteworthy that similar transformations have not been reported in other compounds of this structure type. To date only compounds containing $\mathrm{Zr}$ and $\mathrm{Hf}$ have been found to produce these transformations, but not all of them do so. The compound $\mathrm{Zr}_{3} \mathrm{Pd}_{4}$ does not transform even at very low temperatures and can be machined in a lathe, whereas $\mathrm{Zr}_{3} \mathrm{Pt}_{4}$ and $\mathrm{Hf}_{3} \mathrm{Pt}_{4}$ exhibit brittle behavior. In addition, pseudobinary alloys of $\mathrm{Zr}_{3} \mathrm{Rh}_{4}$ and $\mathrm{Zr}_{3} \mathrm{Pd}_{4}$ have been reported to exhibit ferromagnetic or superconducting behavior at certain critical compositions. ${ }^{[23]}$ The practical significance of these behaviors will require much further study.

\section{Acknowledgments}

We wish to thank Anthony Giuseppetti for skillfully arc-melting and casting our neutron diffraction samples, Sandy Claggett for the polishing and arduous etching on our metallographic samples, and Juscelino Leão for his assistance with the high-temperature furnace for the collection of the neutron diffraction data. We also thank Ashraf Imam of the Naval Research Laboratory for kindly offering to anneal our samples in his vacuum furnace when ours became inoperable. We acknowledge the support of the Bragg Institute, Australian Nuclear
Science and Technology Organisation (ANSTO) in providing the neutron research facilities used for a portion of this work.

\section{References}

1. L. Topor and O.J. Kleppa, Enthalpies of Formation of Equiatomic Compounds of Titanium, Zirconium and Hafnium with Late Transition Metals, J. Less Common Met., 1989, 155, p $61-73$

2. R.M. Waterstrat, L.A. Bendersky, and R. Kuentzler, Deformation Twinning, Slip, Martensite Formation and Crack Inhibition in the B2-Type $\mathrm{Zr}_{50} \mathrm{Pd}_{35} \mathrm{Ru}_{15}$ Alloy, MRS Symp. Proc., 1992, 246, p 115-120

3. A.C. Larson and R.B. VonDreele, General Structure Analysis System (GSAS), Los Alamos National Laboratory Report No. LAUR 86-748, 2005

4. B.H. Toby, EXPGUI, a Graphical User Interface for GSAS, $J$. Appl. Crystallogr., 2001, 34, p 210-213

5. J.K. Stalick and R.M. Waterstrat, The Zirconium-Platinum Phase Diagram, J. Alloys Compd., 2007, 430, p 123-131

6. P.J. Meschter and W.L. Worrell, An Investigation of High Temperature Thermodynamic Properties in the Pt-Zr and Pt-Hf Systems, Met. Trans. A, 1977, 8A, p 503-509

7. A.E. Dwight and P.A. Beck, Close-Packed Ordered Structures in Binary $\mathrm{AB}_{3}$ Alloys of Transition Elements, Trans. AIME, 1959, 215, p 976-979

8. A. Raman and K. Schubert, Strukturuntersuchungen in einigen zu $\mathrm{T}^{4}-\mathrm{T}^{9}$ homologen und quasihomologen Legierungssystemen, Z. Metallk., 1964, 55, p 704-710

9. J.K. Stalick, K. Wang, and R.M. Waterstrat, The Crystal Structure and Phase Transition of $\mathrm{Hf}_{2} \mathrm{Pt}_{3}, J$. Phase Equilib. Diffus., 2013, 34, p 385-389. doi:10.1007/s11669

10. P. Krautwasser, S. Bahn, and K. Schubert, Strukturuntersuchungen in den Systemen Ti-Pd und Ti-Pt, Z. Metallk., 1968, 59, p 724-729

11. T. Hara, T. Ohba, K. Otsuka, and M. Nishida, Phase Transformation and Crystal Structures of $\mathrm{Ti}_{2} \mathrm{Ni}_{3}$ Precipitates in Ti-Ni Alloys, Mater. Trans., 1997, 38, p 277-284

12. D.T. Cromer, A.C. Larson, and R.B. Roof, The Crystal Structure of $\mathrm{Pu}_{3} \mathrm{Pd}_{4}$, Acta Crystallogr. Sect. B, 1973, B29, p 564-567

13. J.K. Stalick and R.M. Waterstrat, unpublished results

14. L.A. Bendersky and R.M. Waterstrat, Incommensurate Structure of the Phase $\mathrm{Zr}_{3} \mathrm{Rh}_{4}$, J. Alloys Compd., 1997, 252, p L5L7

15. J.L. Jorda, T. Graf, L. Schellenberg, J. Muller, K. Cenzual, J.C. Gachon, and J. Hertz, Phase Relations, Thermochemistry and Superconductivity in the $\mathrm{Zr}-\mathrm{Rh}$ System, J. Less Common Met., 1988, 136, p 313-328

16. J.K. Stalick, L.A. Bendersky, and R.M. Waterstrat, OneDimensional Disorder in $\mathrm{Zr}_{9} \mathrm{M}_{11}(\mathrm{M}=\mathrm{Ni}, \mathrm{Pd}, \mathrm{Pt})$ and LowTemperature Atomic Mobility in $\mathrm{Zr}_{9} \mathrm{Ni}_{11}, J$. Phys. Condens. Matter, 2008, 20, p 285209 (10 pp)

17. A.E. Dwight, R.A. Conner, Jr., and J.W. Downey, Equiatomic Compounds of the Transition and Lanthanide Elements with Rh, Ir, Ni and Pt, Acta Crystallogr., 1965, 18, p 835-839

18. M.V. Nevitt and L.H. Schwartz, Zirconium and Hafnium Phases Isostructural with $\mathrm{Ti}_{2} \mathrm{Ni}$, Trans. Metall. Soc., 1958, 212, p 700-703 
19. P. Duwez, The Allotropic Transformation of Hafnium, J. Appl. Phys., 1951, 22, p 1174-1175

20. R.B. Russell, On the Zr-Hf System, J. Appl. Phys., 1953, 24, p 232-233

21. M.A. Gharghouri, Neutron Diffraction Techniques for Alloy Characterization and Development, Mater. Sci. Forum, 2006, 519-521, p 1379-1384
22. O. Levy, G.L.W. Hart, and S. Curtarolo, Hafnium Binary Alloys from Experiments and First Principles, Acta Mater., 2010, 58, p 2887-2897

23. L.H. Bennett, R.M. Waterstrat, L.J. Swartzendruber, L.A. Bendersky, H.J. Brown, and R.E. Watson, Magnetism and Incommensurate Waves in $\mathrm{Zr}_{3}\left(\mathrm{Rh}_{1-x} \mathrm{Pd}_{x}\right)_{4}, J$. Appl. Phys., 2000, 87, p 6016-6018 